\title{
SOBRE O FENÔMENO DA INTERATIVIDADE
}

Lucyane De Moraes ${ }^{1}$

\section{Resumo}

Trabalhar com componentes de hardware e software, até então destinados à execução exclusiva de tarefas computacionais objetivas, já não parece mais irrelevante para o discurso artístico, fato esse que legitima à Estética Contemporânea a apropriação de uma gama de possibilidades, incluindo a própria análise das relações entre tecnologia e arte. Cabe lembrar que a discussão sobre o fazer artístico por meio de computadores, mesmo de maneira inicial, já aparece por volta dos anos de 1950, em meio a um debate que estava longe de terminar. Para a atualidade do debate, tendo por base um novo estatuto linguístico instaurado pelas tecnologias digitais, é necessário, sob uma ótica distinta, refletir sobre a possibilidade de experienciar a relação entre tempo e espaço sucessividade e simultaneidade - por meio da imersão interativa nos ambientes virtuais. Sendo assim, este artigo propõe o exame de textos elaborados por teóricos que fundamentaram o chamado ramo da comunicação avançada, discutindo o potencial estético apregoado pelos adeptos da intitulada "arte virtual", por meio da também denominada "realidade aumentada". A partir da reflexão sobre os modos de produção da arte nos dias de hoje, baseada na mediação entre necessidade e ação tecnológica, talvez seja possível conceituar e dar sentido histórico concreto a uma ideia de desenvolvimento técnico como forma de potencialização do humano.

Palavras-chave: Arte, Sociedade, Técnica, Humanismo.

\section{ON THE INTERACTIVITY PHENOMENON}

\begin{abstract}
The use of hardware and software components, in principle intended exclusively for objective computational tasks, no longer seems something foreign to artistic discourse, a fact that enables Contemporary Aesthetics to appropriate a range of possibilities, including the analysis of the relationship between technology and art. It must be said the discussion of artistic practice through computers, even in its early days, arises around the 1950s, introducing a debate that was far from over. For its current time, based on a new linguistic statute established by digital technologies, it is necessary, from a different perspective, to reflect on how it is possible to live the relational experience between time and space - successive and simultaneous instances- through interactive immersion in virtual environments. Thus, this paper proposes to reflect on essays written by theorists who founded the so-called advanced communication, discussing the aesthetic potential defended by the followers of the so-called "virtual art", through the also called "augmented reality". In order to reflect on the forms of art production today, supported by the mediation between necessity and technological development, it may be possible to both conceptualize and lend a precise historical sense to an idea of technical development aimed at the power of the human.
\end{abstract}

Keywords: Art, Society, Technique, Humanism.

1 Doutora em Filosofia. Atua nas seguintes áreas de pesquisa: Teoria Tradicional e Teoria Crítica, Filosofia da Técnica e da Tecnologia, Estética e Filosofia Social, abordando temas como: Indústria Cultural, Cultura Material e Imaterial e Recepção de novas Mídias da Imagem e do Som. Atualmente vem se dedicando à investigação dos fenômenos ligados aos media digitais, com ênfase nos desdobramentos dessas recentes tecnologias. É autora de diferentes artigos acadêmicos e capítulos de livros com temas socioculturais. Endereço para contato: cinetoscopio@yahoo.com.br. http://orcid.org/0000-0003-3648-3481 


\section{Nota Introdutória}

Em um mundo contemporâneo cada vez mais definido pela esfera técnica no âmbito dos fins, talvez seja possível dizer - em uma dimensão bastante ampla - que a reflexão filosófica não tem dado a ênfase merecida à questão da técnica. Apesar de a sociedade contemporânea viver sob a impressão de uma espécie de era tecnológica, cujos benefícios aparentes insinuam estados absolutos de conforto e liberdade individual, ainda assim o que se percebe é que o esforço filosófico parece ainda dever à técnica a dimensão prioritária de sentido crítico que a mesma demanda, o que causa estranheza tendo em vista o fato de a sua reflexão em termos éticos remontar pelo menos à filosofia antiga, registrada, por exemplo, nos diálogos de Platão, para citar apenas uma de suas maiores expressões.

Diversa em seus motivos, essa ocorrência pode ser atribuída à supremacia do pensamento científico sobre as demais formas do conhecimento, fato esse que ilustra a constatação do filósofo alemão Max Horkheimer de que "hoje existe quase um consenso de que a sociedade nada perdeu com o declínio do pensamento filosófico, já que um instrumento de conhecimento muito mais poderoso tomou seu lugar, a saber, o pensamento científico moderno" (Horkheimer, 2002, p. 69).

Se o século XIX marca a consolidação da ciência moderna, caracterizada pela separação entre esta e a filosofia e se, como consequência, o mundo contemporâneo vive os processos técnicos de forma irrefletida, pode-se dizer que essas contradições foram dimensionadas no âmbito de um processo hegemônico que culminou na transformação do próprio significado daquilo que em termos comuns se entende hoje por tecnologia, para além da aplicação de dados científicos circunscrita no campo das sociedades produtivas. Decorre daí a importância de se pensar filosoficamente a esfera tecnológica em termos críticos, para além da vivência do conjunto de artefatos do mundo industrial, com vistas a uma aplicação ética de recursos fundamentais para se compreender as vertiginosas mudanças das sociedades modernas.

\section{Os primórdios da interatividade}

Rastreando a história recente nota-se que a palavra "cibernética" foi utilizada em 1948 pelo matemático estadunidense, então professor do Instituto de Tecnologia de Massachusetts (MIT), Norbert Wiener, em seu livro, Cybernetics, or Control and

\begin{tabular}{|l|l|l|l|l|}
\hline Qenista Dialectus & Ano 10 & n. 23 & Maio - Agosto 2021 & p. 194 - 209 \\
\hline
\end{tabular}


Communication in the Animal and Machine, como forma de nomear uma pretendida nova ciência voltada para o estudo de fenômenos naturais e artificiais tendo como base a teoria do controle e comunicação de seres vivos e máquinas nos processos sociais. Partindo da palavra

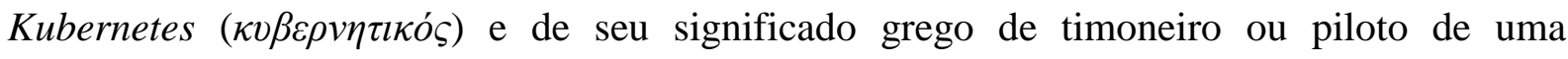
embarcação, Wiener, ao que parece sem saber, se refere a um termo que Platão utiliza em Gorgias e Político como analogia à arte (téchne) de dirigir ou governar a polis.

Certo é que, em seu livro, Cibernética e sociedade: o uso humano dos seres humanos, Wiener, desenvolveu as bases para o desenvolvimento da cibernética como se conhece hoje, compreendendo "o estudo das mensagens como meio de dirigir a maquinaria e a sociedade, o desenvolvimento de máquinas computadoras e outros autômatos como tais" (Wiener, 1954, p. 15). Segundo o próprio autor, desde fins da Segunda Guerra Mundial ele vinha trabalhando com teoria das mensagens, mais especificamente a teoria da transmissão de mensagens da engenharia elétrica, compreendendo a teoria das mensagens como uma teoria das probabilidades.

A cibernética teve seu período áureo durante as primeiras décadas que sucederam a Segunda Guerra Mundial, declinando pouco a pouco nos anos seguintes, devido, segundo se atribui, ao fato de suas ideias terem sido consideradas demasiadamente difusas e residuais. De qualquer forma, não deixa de chamar atenção o caráter de objetividade que cerca a filosofia, por assim dizer, que fundamentou a elaboração da cibernética, notadamente presente, por exemplo, no título original em inglês do citado livro de Wiener: The human use of human beings, bem como no subtítulo de sua obra citada anteriormente, de 1948, assinalando o “controle e comunicação de seres vivos e máquinas" nos processos sociais.

No entanto, pode-se dizer que sua derrocada se deveu principalmente ao advento daquilo que é considerado como o primeiro computador já criado, ou seja, a chamada máquina de Turing que atuava na formalização do conceito de algoritmo e computação de dados. Concebida teoricamente pelo matemático, criptoanalista e cientista da computação londrino, Alan Turing, em fins dos anos trinta, uma versão física de sua máquina computadora foi construída para uso militar no início da década de quarenta com o objetivo de quebrar os códigos de mensagens secretas criptografadas pela máquina eletromecânica denominada Enigma, inventada e patenteada, no ano de 1918, pelo engenheiro eletromecânico alemão Arthur Scherbius, com fins inicialmente comerciais.

A versão utilizada pelas forças militares da Alemanha nazista durante a II Guerra Mundial foi uma adaptação aperfeiçoada da original, que permitia a codificação e decodificação

\begin{tabular}{|l|l|l|l|l|}
\hline Qenista Dialectus & Ano 10 & n. 23 & Maio - Agosto 2021 & p. 194 - 209 \\
\hline
\end{tabular}


de mensagens de forma automática. Por sua vez, a Máquina de Turing, intitulada por seu criador como Colossus, também conhecida como máquina universal, que decifrou os códigos Enigma durante a Segunda Grande Guerra, tinha funções determinadas por um programa armazenado dentro de um cartuxo de memória (software), um modelo restrito de computador cujas operações se restringiam apenas a aspectos de funcionamento lógicos. Ainda assim, considerase que a sua invenção contribuiu de forma efetiva para a criação de microcomputadores, tornando-se um protótipo dos computadores modernos.

Apenas algumas décadas após o desenvolvimento da Máquina de Turing, a internet, originalmente nomeada como ARPAnet - Advanced Research Projects Agency -, iniciou-se como uma rede de computadores nos anos de 1960, numa reação dos Estados Unidos à conquista tecnológica da então União Soviética com o lançamento do primeiro satélite artificial, o Sputnik 1 (marco da ciência que possibilitou o acesso de informações valiosas aos cientistas modernos). A partir de então, agências e Universidades nos EUA criaram redes próprias, sendo a da Universidade de Stanford a primeira a conectar computadores em locais separados, deixando cair por terra a versão que enfatizava somente a vertente militar de sua criação.

Em 1962, o psicólogo e cientista da computação estadunidense, Joseph Licklider, do Instituto Tecnológico de Massachusetts (MIT), primeiro diretor do Information Processing Office (IPTO), já falava em termos da criação de uma "Rede Intergaláctica de Computadores" (Intergalactic Computer Network). À época, o que não se sabia é que se dava início ao que se considera o maior fenômeno midiático do século XX com o estabelecimento de um meio de comunicação em massa que em apenas quatro anos conseguiria atingir aproximadamente 50 milhões de pessoas.

Em 1981, a National Science Foundation NetWork expandiu a ARPAnet em nível nacional com vistas ao desenvolvimento da pesquisa científica por computadores. A ARPAnet adotou o sistema técnico denominado Protocolo de Controle de Transmissão (Transmission Control Protocol - TCP) que permitia que o tráfego de informações fosse encaminhado de uma rede para outra, separando-se da rede militar (MILnet) por meio de um subsistema de uso público voltado para pesquisas.

Todas as redes conectadas pelo endereço IP na Internet - infraestrutura que conecta todos os pontos de uma rede - começaram a se comunicar e, assim, tal subsistema foi projetado conectando diferentes computadores. A National Science Foundation NetWork (NSFNET), programa de financiamento da internet patrocinado pela National Science Foundation (NSF), acabou se tornando um recurso vinculado aos centros de supercomputação dos EUA, com

\begin{tabular}{|l|l|l|l|l|}
\hline Qenista Dialectus & Ano 10 & n. 23 & Maio - Agosto 2021 & p. 194 - 209 \\
\hline
\end{tabular}


capacidade de dar vazão a grandes fluxos de dados, conectando pesquisadores a redes regionais e, a partir daí, para aproximadamente 200 redes subsidiárias. A transição da ARPAnet para o protocolo de sistema público através de IP se deu em 1983, acelerando o crescimento da demanda do uso tecnológico de conexão na internet.

Com isso, a ARPAnet disseminou-se rapidamente não só entre as Universidades e sistema de ensino médio nos EUA, mas também a serviço do desenvolvimento do comércio e da indústria, por meio de provedores de serviços. Em 1989, Tim Berners-Lee, do CERN, criou o conhecido protocolo de transferência de hipertexto, HyperText Transfer Protocol (http), uma padronização que deu às diversas plataformas de computadores a capacidade de acessar sites de internet, permitindo o envio de dados criptografados que possibilitaram o início de transações comercias. Por esta razão, Berners-Lee é lembrado como o pai da Rede Mundial de Computadores - World Wide Web (www). Com isso, a National Science Foundation NetWork assumiu o papel de backbone (espinha dorsal) de toda a rede naquele país, sendo a ARPAnet gradualmente extinta a partir de 1990.

O navegador da Web Mosaic, criado em 1993 na Universidade de Illinois UrbanaChampaign foi o elemento-chave desenvolvido pela National Science Foundation Network, sendo a primeira web browser a ser usada no Windows (além do UNIX), que abriu a navegação na net para o público em geral, apresentando imagens alinhadas com textos e possibilitando o surgimento das várias outras interfaces gráficas que conhecemos hoje, capaz de processar diversas linguagens como, por exemplo, a barra de endereço virtual URL (Uniform Resource Locator), em português conhecida como Localizador Padrão de Recursos, bem como outras opções de retorno/avanço/reinicio para a adequada visualização de páginas da Web pelos usuários.

A partir de 1995, os provedores criaram pontos de acesso de rede que permitiram que o comércio com fins lucrativos pela internet fosse desenvolvido. Com isso, a internet deixou de ser um mero e pouco conhecido recurso de pesquisa, tornando-se um fenômeno tecnológico utilizado por mais de quatro bilhões de pessoas em menos de sessenta anos.

De acordo com o sociólogo italiano Alessandro Dal Lago, em meados do ano de 2016 a Internet nos EUA contava com 287 milhões de usuários, totalizando 85\% da população, quantificação essa que representava à época $1,8 \%$ dos usuários de todo o mundo, deixando antever um quadro situacional que vai muito além do desenvolvimento da pesquisa e da informação: "no mercado da Web, o que importa é a venda - e, portanto, a livre circulação de produtos, independente do seu significado ideológico" (Dal Lago, 2017, p. 17), demonstrando

\begin{tabular}{|l|l|l|l|l|}
\hline Gevista Dialectus & Ano 10 & n. 23 & Maio - Agosto 2021 & p. $194-209$ \\
\hline
\end{tabular}


o enorme potencial da Web voltado para transações comerciais em nível global: "o controle de nossa identidade como consumidores tem, de fato, propósitos puramente econômicos, tornando-se uma espécie de marketing global” (Dal Lago, 2017, p. 17).

Por sua vez, o historiador da arte e teórico das mídias alemão, Oliver Grau, sob a ótica da produção e difusão artística, procura antecipar os caminhos que a internet poderá percorrer e a função que deverá desempenhar em um futuro próximo, ao afirmar que "assim que a internet estiver capacitada, estarão disponíveis online os espaços imagéticos que atualmente só podem ser vistos sob a forma elaborada e dispendiosa de instalações em festivais ou museus de mídia" (Grau, 2007, p. 32). O autor se refere à ideia de que em um dito espaço virtual, ou seja, de ilusão, o observador em estado imersivo é tomado por uma ilusória impressão espacial, impressão essa pressuposta por sua imaginação. Em outras palavras, afirma que a condição do "estar" em um ambiente virtual é consequência de um ato vivenciado - não presumido - unicamente em pensamento.

Já Dal Lago, em uma perspectiva crítica, se reporta à questão dessa vez assinalando a determinação que envolve esse universo, dimensionando a função comportamental que os sistemas midiáticos computacionais desempenham na formação do caráter dos usuários expostos a situações de imersão interativa: “o mundo da rede produz uma ilusão de independência à qual uma submissão inconsciente é associada" (Dal Lago, 2017, p. 17). A propósito, sobre a suposta tendência de atribuir caráter condicionalmente emancipatório à interatividade computacional, vale lembrar a ponderação de Dal Lago segundo a qual "os cidadãos sempre tiveram o papel passivo de espectadores, mesmo quando ativamente interessados" (Dal Lago, 2017, p. 17). De acordo com o sociólogo, a liberdade de expressão nas esferas midiáticas computacionais é condicionada por um conjunto de pressupostos (linguagens e protocolos da Web, algoritmos de busca, motores, etc.) os quais leva o usuário a não expressar opiniões de forma neutra.

E ao indagar sobre a predominância do universo virtual frente ao real, Dal Lago avalia que a permanência de tal condição deverá prevalecer "pelo menos até o estabelecimento da rede como um ambiente social mais qualificado", uma vez que, enquanto "esfera artificial e programada de 'liberdade' comunicativa” pode-se dizer que é inerente ao conceito de virtual "a ilusão produzida pela própria natureza da Web" (Dal Lago, 2017, pp. 14-17).

Sob outra ótica, o teórico da arte italiano, Roberto Diodato, diz que em um ambiente virtual, criado eletronicamente por uma máquina de informática, não se aprende pelo método tradicional de estudo científico, mas sim pelo chamado procedimento de imersão, que pode

\begin{tabular}{|l|l|l|l|l|}
\hline Qenista Dialectus & Ano 10 & n. 23 & Maio - Agosto 2021 & p. 194 - 209 \\
\hline
\end{tabular}


provocar experiências perceptivas no usuário. Além disso, segundo o autor italiano, “a imersão pode se dar, e de fato se dá, mas como qualidade de uma experiência inconfundível daquela que consideramos «real»" (Diodato, 2011, p. 26), ou seja, por uma experiência de interatividade "virtual", sendo o procedimento de imersão medido pela qualidade dessa experiência do usuário.

Em outras palavras, o nível de imersão se dá de acordo com o nível da interatividade e quanto maior essa interatividade, mais qualificada a imersão. Com isso, o autor italiano alude ao fato de que, enquanto um procedimento análogo à comunicação, a interatividade, ou seja, “a possibilidade de manipular a própria perspectiva convertendo-a em um lugar de experiência se conjuga com a possibilidade de aprender por imersão", processo esse que se dá através da “apropriação de pontos de vista de outros usuários" (Diodato, 2011, p. 32), denotando claramente o procedimento inerente à comunicação em geral de simetria entre emissores e receptores.

Pode-se dizer que em relação à arte no meio virtual a estrita acepção comunicacional inerente à interatividade corresponde diretamente a uma implícita condição de perda do significado da obra de arte, dado o absoluto predomínio do aspecto comunicativo em detrimento da própria existência da expressão. Com isso, Diodato alude que o virtual, não sendo a reprodução de uma obra de arte real, mas sim a sua representação, se constitui como um “corpo-sutil, entidade híbrida objeto-imagem, e sua aparência, seu existir-como imagem, é por essência interativa" (Diodato, 2011, p. 79).

Sob essa ótica, pode-se dizer que a representação é uma referencia relacional que leva em conta, no que tange à imagem, a ocorrência de seu reflexo, invertido, sendo mais do que propriamente a sua aparência, ao contrário de uma reprodução, constituída em um ambiente físico enquanto imagem exata de um original percebido na realidade. Voltando à questão, Diodato, ao rejeitar o conceito de simulacro, afirma que a representação do virtual, em sua aparência, se dá em um sentido não imitativo de mimese, uma vez que a imagem digital não é simplesmente "imagem-de", ou seja, a reprodução de uma imagem.

\section{O universo interativo virtual}

A partir da constatação de que "o uso da interatividade como variável em investigações empíricas aumentou drasticamente com o surgimento de novos canais de comunicação, como a rede mundial de computadores" (Kiousis, 2002, p. 355), para teóricos do

\begin{tabular}{|c|c|c|c|c|}
\hline Qovista Oialectus & Ano 10 & n. 23 & Maio - Agosto 2021 & p. $194-209$ \\
\hline
\end{tabular}


chamado ramo da comunicação avançada, como, por exemplo, Eduard J. Downes, Sally J. McMillan, Sheizaf Rafaeli e Spiro Kiousis, em sentido geral, entende-se por interatividade uma forma de comunicação em ambientes mediados por computador, com vistas tanto ao monitoramento de informações quanto a direcionamentos comunicacionais, em uma acepção invariavelmente associada às atuais tecnologias computacionais.

Sob outro aspecto, a interatividade caracteriza também a habilidade de influenciar pessoas ou grupos a partir de estímulos relacionais tanto de forma direta quanto indireta, sendo ambas as acepções circunscritas a ações de comunicação mediada, podendo ser aplicadas não somente às esferas empresariais, mas também políticas, entre outras. Não se diferindo no fundamental, constata-se que ambas as instâncias - ligadas a relações de troca e voltadas para o controle e administração tanto de recursos constantes quanto de variáveis - apresentam funções comunicacionais, ou em outras palavras, interativas comunicacionais por meio de geração de conteúdos.

Ainda, de acordo com os teóricos da CMC (Comunicação Mediada por Computador), o campo da interatividade é caracterizado pelo estabelecimento dos seguintes fatores distintos, mas sincronizados em termos operacionais: função comunicacional (nível de controle, desempenho e proposição), estrutura tecnológica (aplicação de múltiplas formas de comunicação mediada por computador) e percepção dos indivíduos (análise dos níveis de relacionamento entre grupos), fechando um ciclo sistêmico.

Apesar do nível hierárquico de organização racional apresentado, Sheizaf Rafaeli afirma que "interatividade é um termo amplamente utilizado de forma intuitiva, sendo um conceito não muito bem definido" (Rafaeli, 1988, p. 110), afirmação essa corroborada em parte por Downes e McMillan nos seguintes termos: "a literatura sobre interatividade inclui muitos pressupostos e algumas definições, mas poucas ferramentas para operacionalizar o conceito de interatividade em ambientes mediados por computador" (Downes \& Mcmillan, 2000, p. 157), confirmando não somente o caráter empírico atribuído à interatividade, mas sobremaneira a sua inserção absoluta no âmbito da comunicação e informação ligado à administração do mundo do capital.

Segundo Rafaeli, “o estudo da interatividade faz parte da evolução da ontologia e da epistemologia da tecnologia da comunicação em geral e do computador como mídia em particular" (Rafaeli, 1988, p. 112). E aludindo ao fato de que "o estudo das novas relações de comunicação, incluindo o das novas mídias, seus usos e públicos dirigidos, estão adquirindo um amadurecimento, partindo de um estado não refinado de relatividade para um

\begin{tabular}{|l|l|l|l|l|}
\hline Qonista Dialectus & Ano 10 & n. 23 & Maio - Agosto 2021 & p. 194 - 209 \\
\hline
\end{tabular}


empreendimento mais focado", o teórico afirma que "a interatividade se apresenta sob uma espécie de viés de interação social”, sendo "interatividade quintessencialmente um conceito de comunicação [...] difícil de descrever sem apertos de mão” (Rafaeli, 1988, pp. 112-113).

O construto de interatividade aborda progressivamente os seus "ques" (intervenção completa), "quens" (grandes e experientes usuários, consumidores experientes, inovadores) e suas razões de ser (várias tecnologias e diversas qualidades: complexidade, consistência, concisão, custos e assim por diante). No cumprimento desses requisitos, a interatividade é como algumas outras áreas de interesse na nova literatura da tecnologia da comunicação (orientação temporal da mídia, graus de controle do fluxo de comunicação, tarefas versus viés socioemocional de um meio, propriedades de busca de informações de uso da mídia) (Rafaeli, 1988, pp. 112-113).

Assim é que Rafaeli identifica a interatividade como uma construção teórica que lida com as origens do fascínio e atração inerentes a grupos relacionados à mediação por computadores, contribuindo para o esforço de uma definição que abarque a amplitude do campo a ser delineado. De qualquer forma, o autor irá inicialmente definir, em um sentido não muito claro, a interatividade como "uma expressão da extensão que, em uma dada série de relações de comunicação, qualquer terceira (ou última) transmissão (ou mensagem) está relacionada ao grau em que as trocas anteriores se referem a transmissões primeiras”, posteriormente redefinindo o conceito em termos menos enigmáticos, ou seja, como "a extensão na qual as mensagens em uma sequência se relacionam umas com as outras e, especialmente, a extensão na qual as mensagens posteriores se referem de forma relacional com as mensagens anteriores" (Downes \& McMillan, 2000, p. 159).

Por sua vez Downes e McMillan, baseados em conceitos encontrados na literatura específica sobre o tema, realizam pesquisas de opinião junto a indivíduos envolvidos com as emergentes tecnologias de comunicação objetivando avaliar as percepções daqueles, enquanto usuários, sobre os processos de interatividade em ambientes mediados por computador. Segundo os autores, a análise qualitativa das respostas revelou múltiplos temas que confirmam o conceito de interatividade, levando-os a concluir que "o termo «interatividade» foi usado para descrever produtos que vão desde bonecas que roncam e folhetos difundidos na web até videogames e transações on-line" (Downes \& McMillan, 2000, p. 157).

Sob essa perspectiva os pesquisadores, procurando determinar o campo de ação e as formas de atuação no âmbito da interatividade, postulam a necessidade imperativa de se adotar uma definição mais concreta para a aplicação do conceito, afirmando que "estudiosos

\begin{tabular}{|l|l|l|l|l|}
\hline Qenista Dialectus & Ano 10 & n. 23 & Maio - Agosto 2021 & p. 194 - 209 \\
\hline
\end{tabular}


empregaram o termo para se referir a tudo, de trocas presenciais à comunicação mediada por computador" (Downes \& McMillan, loc. cit.), ampliando demasiadamente o seu entendimento, contribuindo ainda mais para a sua não definição em termos mais adequados: "grande parte da literatura, popular e acadêmica, usa o termo 'interatividade' com pouca ou nenhuma intenção de defini-lo. Mesmo quando as definições são encontradas, elas são frequentemente contraditórias" (Downes \& McMillan, 2000, pp. 157-158). Em concordância com os autores, Spiro Kiousis, irá afirmar que "embora muitos estudiosos tenham empregado o conceito em análises realizadas, as definições teóricas e operacionais foram excessivamente dispersas e incoerentes" (Kiousis, 2002, p. 355).

Ainda assim, Downes \& McMillan referindo-se ao fato de que "somente nos últimos dez ou quinze anos estudiosos da tradição da comunicação de massas começaram a examinar a natureza da interatividade na comunicação mediada por computadores" (Downes \& McMillan, 2000, p. 158), reconhecem as iniciativas empreendidas por considerados expoentes da pesquisa sobre a interatividade citando nomes como o professor e estudioso no campo das comunicações e psicologia social Melvin L. DeFleur, o Professor de Comunicação e Gestão de Mídia na Escola de Pós-Graduação em Negócios da Fordham em Nova York, Denis Everette e, especialmente, o já citado Sheizaf Rafaeli.

Oliver Grau, sob uma ótica empírica, considera a questão para além da esfera teórica, buscando dimensionar tanto a interatividade quanto a imersão em um sentido prático, mais afeito mesmo ao universo tecnológico e midiático, relacionado à própria vivência do indivíduo objeto do processo de imersão interativa.

Em resumo, também em um sentido propriamente tecnológico, Roberto Diodato, citando uma sentença do educador italiano Pier Cesare Rivoltella, alude que "a interatividade, por sua parte, designa «o nível de participação dos usuários em modificar a forma e o conteúdo de um ambiente de mídia»” (Rivoltella apud Diodato, 2011, p. 25), reafirmando o sentido de vivência do indivíduo aludido por Grau. Já no campo específico da arte, ao afirmar que "a imagem digital não é uma «imagem» propriamente dita, mas um corpo-imagem”, Diodato se refere ao que ele denomina como corpo virtual, ou seja, uma imagem digital interativa, "um corpo eletrônico e, portanto um conjunto de átomos [...], uma quantidade notável de dados [...] cuja aparência, seu existir como imagem, é por essência interativa” (Diodato, 2011, p. 20).

Elucidando ainda o conceito, avalia que o corpo virtual "não existe como corpo exceto na interatividade, é uma interação, um objeto-evento: uma ação (relação de interatividade) que é um corpo (corpo virtual) enquanto possui as características que geralmente

\begin{tabular}{|l|l|l|l|l|}
\hline Rovista Dialectus & Ano 10 & n. 23 & Maio - Agosto 2021 & p. 194 - 209 \\
\hline
\end{tabular}


atribuímos aos corpos", concluindo que "o corpo virtual permanece no tempo" (Diodato, 2011, p. 36). A isso, equivale dizer que enquanto representação holográfica do mundo, recriação não topológica do real, o virtual não intui um espaço. Enquanto aparição a existência da arte virtual pressupõe necessariamente o acesso de um usuário a uma máquina ou outro dispositivo eletrônico qualquer, configurando a condição de interatividade inerente.

Por oportuno, o ensaísta e ex-diretor interino para Ciências Sociais e Humanas da UNESCO, Philippe Quéau, ao afirmar que "as imagens permitem a percepção sensível de modelos inteligíveis" - pegando emprestado o conceito de imagem de Platão -, busca explicar como opera tal relação no âmbito virtual, concebido enquanto forma de matematização do espaço: "um modelo é uma concepção formal, anotada com símbolos lógico-matemáticos e memorizada em forma de programa informático" (Quéau, 1995, pp. 23-24). Por sua vez, o autor assinala também como complemento, o sentido de mediação inerente a ambas as esferas, aludindo ao fato de que "a imagem é a representação sensível pela qual se pode tentar compreender o modelo", discernindo-as em termos operacionais: "a imagem propõe uma representação visível e o modelo uma representação inteligível [...] O modelo e a imagem se constituem mutuamente" (Quéau, loc., cit.), resumindo em termos sensitivos o potencial interativo que possibilita o ambiente virtual, ou em outras palavras, a sensibilidade para "estar" em um ambiente criado eletronicamente.

Refere-se com isso, a um complexo de qualidades perceptivas que pode incluir cores, sons e imagens não encontradas na natureza, definidas artificialmente, de forma não real. Sendo assim, o virtual aspira a uma espécie de supra-realidade que transcende o real mesmo como aparência, gerando uma contradição com sua própria forma não existente na realidade. $\mathrm{O}$ virtual visa o real, mas, diferentemente do virtual, do real participam os seres vivos.

Aliás, Diodato assevera que "em um ambiente virtual o que é percebido pelo usuário como coisa é em realidade um evento, a atualização provisória de algo virtual, que existe somente, em sua atualidade, como função da relação interativa", ratificando a ideia de existência do virtual enquanto algo temporal, condicionada a uma máquina acionada por um usuário. O virtual só existe na interatividade, sendo essa a sua natureza. Ou, nas palavras do autor, "é real, precisamente enquanto virtual” (Diodato, 2011, pp. 35-36).

No entanto, sendo a percepção real da realidade constituída pelo sujeito em um ambiente materializado fisicamente, pode-se dizer em sentido oposto que a realidade virtual, enquanto ambiente diferenciado do real suprime o sujeito na imaterialidade do objeto. "o 
dualismo do modelo e da imagem, do inteligível e do sensível cria, de fato, certa distância entre o sujeito e o mundo virtual, entre a compreensão e a percepção" (Quéau, 1995, p. 24).

Entende-se com isso, que, para o sujeito, a experiência direta da realidade pressupõe a constituição de um ambiente, por assim dizer, coerente, estabelecido no tempo e espaço real diferenciado, diverso de um "espaço-tempo" indistinto no qual o virtual acontece como aparição. Sob essa vertente, conforme assevera Quéau, “é fundamental entender bem o dualismo do sensível e do inteligível, da imagem e do modelo, para entender as novas condições da experiência nos mundos virtuais” (Quéau, 1995, p. 24).

No que respeita às artes, o meio virtual também apresenta sentido indiferenciado em relação àquelas que se dão no tempo e as que se dão no espaço. De acordo com Diodato, "um corpo virtual é e não é o mesmo no tempo e no espaço, já que só pode converter-se em acontecimento se houver interação com o usuário" (Diodato, 1991, p. 38). Na indefinição entre direcionalidade sucessiva e concentração simultânea - espaços sonoro e imagético -, o ambiente virtual absolutiza o caráter temporal na supressão do espacial, indiferente a tudo o que se difere no âmbito da materialidade física.

Como princípio de não realidade da existência autônoma dos objetos, na denominada realidade virtual, a ênfase na aparência é coerente porque esse meio já surgiu como aparição, representação do real na imaterialidade do objeto-imagem, para usar a expressão de Diodato. "O corpo virtual é a sua aparência; ou seja, enquanto algo virtual é sua história, a história de sua conversão em fenômeno a partir de uma série de relações que constituem um ambiente virtual" (Diodato, 1991, p. 40). Sob essa ótica, pode-se dizer que a arte virtual se pretende a-histórica. Não resume nenhuma permanência e, portanto, enquanto aparição não guarda nenhum testemunho de existência.

Com efeito, equivale dizer, em outro contexto, que, enquanto essência do não real, aparência de algo aparente, o que confere a autoridade ao virtual consiste exatamente em sua não permanência, determinando por condição implícita o seu aspecto a-histórico. Mas, a história é instrumento possível de re-originar o estado da técnica, desencantando-a. O seu nexo pode adquirir sentido de ferramenta teórica desmistificadora de certa concepção de virtual caracterizada como imperativo de produção que pensa a comercialização antes mesmo de sua virtual comercialização.

Sob a mediação da crítica teórica, pode-se pensar o enfrentamento de tal concepção a partir da relação entre elementos objetivos e subjetivos em uma mesma análise, ou em outras palavras, considerando a reflexão de ambas as esferas em um mesmo sentido crítico,

\begin{tabular}{|c|c|c|c|c|}
\hline Q Rovista Dialectus & Ano 10 & n. 23 & Maio - Agosto 2021 & p. $194-209$ \\
\hline
\end{tabular}


desvanecendo seu poder "instalado" na consciência dos indivíduos, de forma análoga ao que acontece no âmbito dos sistemas computacionais em relação à máquina.

\section{Considerações finais}

Pode-se pensar um estatuto para a virtualidade técnica que se constitua enquanto utopia produtiva, tarefa essa que aponta para a necessidade de entender os mecanismos de percepção do virtual em sua determinação específica. Ocorre que, devido a sua aparência imaterial, o virtual não se configura enquanto objeto dificultando a sua percepção como um produto industrial. Corpo eletrônico convertido digitalmente, tal recurso resume um processo indireto de participação no real. Por meio da interação com elementos técnicos, o virtual se constitui como aparição, imagem criada de algo aparente que cobra caráter de objeto mediante a sua transformação.

Segundo a investigadora francesa da área de semiologia da imagem, Martine Joly, por imagem entende-se a manifestação visível de "qualquer coisa que se parece com outra coisa" (Joly, 2005, p. 36). Com isso, pode-se pensar que, analogamente às manifestações tradicionais imagéticas produzidas pelo humano, a imagem virtual se parece com aquilo que representa, significando dizer que, diferentemente daquelas que se entende por imagens naturais, o virtual guarda em si o mesmo sentido tradicional de representação atribuído às chamadas imagens fabricadas, como a pintura, o cinema, a fotografia a impressão gráfica e mesmo a gravação sonora.

Mundo das imagens de síntese, o virtual não se difere do modelo formal inteligível, prévio à síntese da imagem. Objetivando aprofundar o conceito, Martine Joly afirma que “imagem - no sentido comum do termo, como no sentido teórico - é um instrumento de comunicação, signo, entre tantos outros, 'que exprime ideias' por um processo dinâmico de indução e de interpretação". Com isso, Joly parece desconsiderar o aspecto de contradição entre as esferas da comunicação e da expressão, talvez mesmo por resumir o conceito de imagem em outro contexto que não o da arte.

Sob tal abordagem semiótica, conclui Joly que a imagem "se caracteriza pelo seu mecanismo (a analogia com o representado e os seus diferentes aspectos) mais do que pela sua materialidade" (Joly, 2005, p. 53). Mas, como se sabe, a imagem não resume somente aquilo que se vê de forma imediata, constituindo a própria ideia de imagem um reflexo, ou seja, uma

\section{6}


dialética que resume o reverso daquilo o qual revela, espelhado, projetando, ao mesmo tempo, a imagem e o seu contrário inerente.

Isso, aliás, já mencionava Platão ao definir a eikonè como aquilo que podia ser visível refletido na superfície das águas, ou seja, uma imagem. Como exemplo, voltando para A República, tem-se Sócrates, que, referindo-se à equivalência entre o Sol e a ideia do Bem em diálogo com Glauco, “observa que se trata de dois poderes; um reina no gênero e na sede do inteligível; o outro, no mundo visível" (509d), sendo o mundo visível constituído por eikones, imagens refletidas n'água. E, ao assinalar que o Sol empresta às coisas visíveis a faculdade de serem vistas e que, portanto, a luz e a visão têm analogia com o Sol, adverte, ainda assim, que seria erro identificá-las com ele.

Em suma, cabe lembrar que tal arrazoado de Platão faz lembrar a observação de Theodor Adorno em relação à dialética, como definição daquilo que, enquanto polos opostos, são diferentes, mas não divergentes. Conforme Platão, “o método dialético é o único que rejeita as hipóteses para atingir diretamente o princípio e consolidar suas conclusões, e que puxa brandamente o olho da alma do lamaçal bárbaro em que vivia atolado, a fim de dirigi-lo para cima, empregando para essa conversão as mencionadas artes, como auxiliares e cooperadoras" (Livro VII, 533c-d). E mais adiante, Sócrates questiona: "não denominas dialético o indivíduo que sabe encontrar a explicação da essência de cada coisa? E quem não chega a esse ponto, na medida em que se mostrar incapaz de dar a si mesmo e aos outros essa explicação, não proclamarás desprovido de inteligência?" (Livro VII, 534b).

Então, para Platão a imagem se constitui como sombra, como o reflexo que se forma a partir de variadas superfícies capazes de produzir, como um espelho, uma cópia de si mesma. Em outras palavras, a imagem e seu modelo de acordo com o critério da verdade e da inverdade, ou seja, do que é verdadeiro e do que é falso, podendo-se aludir às esferas do real e virtual.

De forma análoga pode-se dizer que, sendo a arte mimética em relação à realidade, o virtual é a representação de algo mimetizado da realidade, ou seja, a representação da representação da realidade. Sob a égide da pretensão ao real, o virtual é o oposto do procedimento mimético. Sem um corpo físico, o virtual é um espectro. Imagem sem reflexo, esquecimento de si mesmo, sem permanência histórica. Ao pressupor uma arte em que a tecnologia é estilo, o procedimento virtual faz regredir a percepção simbólica.

Em outras palavras, modernizam-se os meios mantendo os antigos procedimentos hegemônicos impetrados desde os primórdios da tecnologia com vistas à manutenção dos mesmos fins. Daí muitas vezes os velhos efeitos com novos meios. Sob essa perspectiva a-

\begin{tabular}{|c|c|c|c|c|}
\hline Qovista Oialectus & Ano 10 & n. 23 & Maio - Agosto 2021 & p. $194-209$ \\
\hline
\end{tabular}


dialética de uso da técnica, a interatividade virtual se torna o novo sempre-igual (Das Immergleiche) de sentido comum.

Se for certo pensar que os dispositivos técnicos se constituem hoje quase como próteses humanas, também é possível dizer que o homem estabeleceu relação de identidade com tais aparatos, tornados, por analogia, o sujeito dessa relação. A propósito, parafraseando uma sentença de Walter Benjamin em relação ao cinema, é certo dizer que, em relação ao virtual, a empatia entre usuário e arte dá-se por intermédio da máquina, o que faz com que ele assuma a postura desta última. Ainda, segundo Benjamin "o aspecto livre de aparatos da realidade tornou-se aqui o mais artificial, e a visão da efetividade imediata tornou-se a flor azul no país da técnica” (Benjamin, 2019, p. 84).

\section{Referências}

ADORNO, T. Introducción a la dialéctica. Buenos Aires: Eterna Cadencia: 2013.

BENJAMIN, Walter. A obra de arte na era de sua reprodutibilidade técnica. Porto Alegre: L\&PM, 2019.

DAL LAGO, A. Populismo digitale: la crisi, la rete e la nova destra. Milão: Raffaello Cortina Editore, 2007.

DIODATO, R. Estética de lo virtual. Mexico: Universidad Iberoamericana, 2011.

DOWNES, E. J. \& MCMILLAN, S. J. Defining interactivity: a qualitative identification of key dimensions. Londres: New Media \& Society, SAGE Publications, vol. 2, 2000. Disponível em «http://nms.sagepub.com/cgi/content/abstract/2/2/157» Acesso em: 30/05/2021.

GRAU, O. Arte virtual - Da ilusão à imersão. São Paulo: UNESP/SENAC, 2007.

HORKHEIMER, M. Eclipse da razão. São Paulo: Centauro, 2002.

JOLY, M. A imagem e os signos. Lisboa: Edições 70, 2005.

KIOUSIS, S. Interactivity: a concept explication. Londres e Nova Deli: New Media \& Society, SAGE Publications, vol. 4 (3), 2002. Disponível em «http://nms.sagepub.com/cgi/content/abstract/4/3/355» Acesso em: 30/05/2021.

PLATÃO. A República. Belém: Editora UFPA, 2000.

QUÉAU, P. Lo virtual: virtudes y vértigos. Barcelona-México: Paidós, 1995.

RAFAELI, S. Interactivity: From new media to communication. Londres: Sage Annual Review of Communication Research: Advancing Communication Science, Vol. 16, 1988.

\begin{tabular}{|l|l|l|l|l|}
\hline Qenista Dialectus & Ano 10 & n. 23 & Maio - Agosto 2021 & p. 194 - 209 \\
\hline
\end{tabular}


Disponível em «http://gsb.haifa.ac.il/ sheizaf/interactivity/Rafaeli_interactivity.pdf» Acesso em: 30/05/2021.

RIVOLTELLA, P. C. La multimedialità, in C. Scurati (a cura di), Tecniche e significati, Vita e Pensiero. Milão, 2000.

WIENER, N. Cibernética e sociedade: o uso humano dos seres humanos. São Paulo: Cultrix, 1954. 